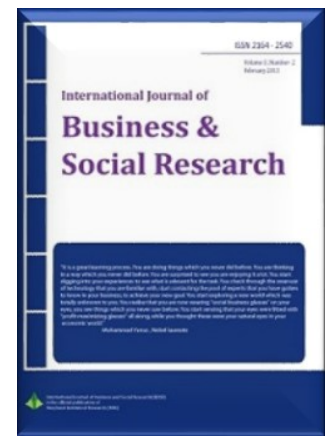

\title{
Perfectionism and Job Burnout: Does Religious Coping Moderate the Relationship?
}

\author{
Sahar Mohamed Badawy', Mohamad Saad Mohamad²
}

\begin{abstract}
This study aimed at investigating the relationship between perfectionism and burnout. Moreover, the moderating effect of religious coping in this relationship was also investigated. The sample of the current study consisted of 210 physicians, with a reasonable mix of demographic characteristics, working in public and private health institutions in the greater Cairo Area. The data were obtained using a structured questionnaire to assess perfectionistic striving, perfectionistic concerns, religious coping and the three dimensions of job burnout, namely, emotional exhaustion, cynicism, and feelings of inefficacy. Significant correlations were obtained between perfectionism and burnout dimensions. However, the moderating effect of religious coping in the relationship between perfectionism and burnout was not obtained. These results were discussed in line with extant literature. Conclusion and policy implications were reported.
\end{abstract}

Keywords: Burnout, Egyptian physicians, perfectionistic concerns, perfectionistic strivings, religious coping. JEL Codes: M54.

Available Online: 10-12-2015

This is an open access article under Creative Commons Attribution 4.0 License, 2015.

\subsection{INTRODUCTION}

Job burnout is an organizational phenomenon that has attracted researchers' attention because of its devastating effects on both individuals and organizations (Maslach, Schaufeli \& Leiter, 2001). The consequences of job burnout include several psychological and physical disorders that vary from mild symptoms (e.g., anxiety and headache) to chronic diseases (e.g., depression and high blood pressure (Maslach et al., 2001), not to mention the organizational effects such as absenteeism, lower productivity, dissatisfaction and intention to leave (Gandi, Wai, Karick, \& Dagona, 2011; Hallsten, Voss, Stark, Josephson, \& Vingård, 2011; Leiter \& Maslach, 2009; Nayeri, Negarandeh, Vaismoradi, Ahmadi, \& Faghihzadeh, 2009; Toppinen, Salla, Anneli, Ari, \& Raija, 2005).

Burnout is caused mainly by chronic organizational stressors. However, several personality traits were found to amplify the effects of organizational stressors on burnout. Perfectionism, as a personality trait,

\footnotetext{
${ }^{1}$ Business Department, British University in Egypt, Cairo, Egypt, E-mail: Sahar.Badawy@bue.edu.eg

${ }^{2}$ Department of Psychology, Cairo University, Giza, Egypt, E-mail: msm_mones@yahoo.com
} 
has been identified in several researches as one of the important correlates of burnout (Kim, Shin, \& Swanger, 2009; Skodova, \& Lajciakova, 2013: Swider, \& Zimmerman, 2010). Nevertheless, previous research reveals inconsistent results regarding the direction of the relationship between perfectionism and burnout. A line of research indicates that perfectionism has an amplifying (i.e., positive) effect on burnout and could lead to several negative outcomes such as depression, eating disorders and chronic fatigue syndrome (Dakanalis, Timko, Zanetti, Rinaldi, Prunas, Carrà, Riva, \& Clerici, 2014; Huggins, Davis, Rooney, \& Kane, 2008; Jahromi, Naziri, \& Barzegaret, 2012; Kempke, Houdenhove, Luyten, Goossens, Bekaert, Wambeke, 2011; Landa, \& Bybee, 2007).

On the other hand, other research evidence indicates that perfectionism has alleviating (i.e., negative) effects on burnout and could lead to some positive outcomes including life satisfaction and academic performance (Bieling, Israeli, \& Antony, 2004; Fedewa, Burns, \& Gomez, 2005; Kanten, \& Yesiltas, 2015; Kobori \& Tanno, 2005; Schiena, Luminet, Philippot, \& Douilliez, 2012). In order to understand the complicated and dynamic relationship between perfectionism and burnout, several mediating and moderating variables were investigated, such as coping styles (Chang, 2012; Li et al., 2014; Luo et al., 2016), and perceived stress (Child, \& Stoeber, 2012; Craiovan, 2014). However, religious coping did not receive much attention as an important moderating variable. The current research is trying to fill this gap by examining the moderating role of religious coping in the relationship between perfectionism and burnout among Egyptian physicians.

This population has special importance for several reasons; first, research indicates that medical care professionals (e.g., physicians and nurses) suffer from high levels of burnout attributed to many work stressors (e.g., workloads, work responsibilities, role conflicts, the intensive personal contact with patients, etc.) (Ozyurt et al., 2006; Shanafelt et al., 2012; Spickard et al., 2002). Second, the negative psychological and organizational consequences among those professionals have profound outcomes on patients, the medical profession, health institutes, and the Egyptian society in general. Third, very few researches have investigated burnout dimensions among Egyptian physicians, and no research was conducted to investigate the moderating role of religious coping in the relationship between perfectionism and burnout in this specific cultural context.

Accordingly, two research questions are identified. First, what is the relationship between perfectionism and job burnout among Egyptian physicians? Second, what is the moderating effect of religious coping on the relationship between perfectionism and burnout in this specific cultural context?

\subsection{LITERATURE REVIEW}

\subsection{PERFECTIONISM AND BURNOUT}

Many psychologists suggested that individuals' personalities affect their interpretations of and reactions to their environments. More specifically, individuals' personalities affect how people perceive, encode, understand and evaluate information from their environments. This mental encoding process is responsible for individuals' behavioural tendencies and reactions (Cano-Garcia et al., 2005). A significant body of research suggests that personality traits affect individual' mental encodings for stressful situations. For example, the big five factors of personality significantly predict job burnout (Swider \& Zimmerman, 2010). Recent research proposed that perfectionism is also an important predictor for job burnout (Chang, 2012)

Perfectionism is a personality trait that has been a subject of debate concerning its effects (Longbottom et al., 2012; Stoeber \& Stoeber, 2009). It was described as a personality trait characterized by striving for excellence and setting excessively high standards for one's performance, accompanied by tendencies toward excessive critical evaluations of one's behaviour (Flett \& Hewitt, 2002). Furthermore, perfectionists over evaluate others' opinions and evaluations for their actions; consequently, they try, by all means, to avoid others' disappointment and disapproval for their actions (Stoeber \& Stoeber, 2009). Traditionally, perfectionism has been associated with maladaptive behaviours, psychosocial adjustment 
problems and a vulnerability to distress (Flett \& Hewitt, 2002; Longbottom et al., 2012). However, recent research has highlighted the good side of perfectionism as an adaptive dimension (Klibert et al., 2005; Kobori, \&Tanno, 2005).

Studies have identified two main dimensions of perfectionism, namely, perfectionistic strivings and perfectionistic concerns. Perfectionistic strivings relate to striving for perfectionism and having high personal standards (Lo \& Abbott, 2013; Stoeber \& Otto, 2006). Research has shown positive relationships between perfectionistic strivings and performance (Bieling, et al., 2004), life satisfaction (Bergman et al., 2007), and academic performance (Eum \& Rice, 2011).

On the other hand, perfectionistic concerns represent worries, concerns and negative feelings due to imperfections (Stoeber \& Otto, 2006), they represent the negative side of perfectionism related to critical self-evaluations and feelings of inconsistency between performance and expectations. They also represent concerns over mistakes, doubts about actions, and others' (e.g., parents, colleagues or supervisors) expectations and criticism (Lo \& Abbott, 2013). Accordingly, perfectionists may experience burnout if they perceive their performance as imperfect (Bieling, et al., 2004; Fedewa, et al., 2005). Perfectionistic concerns were found to be significantly associated with depression (Jahromi, et al., 2012; Schiena, et al., 2012), eating disorders (Dakanalis et al., 2014), chronic fatigue syndrome (Kempke, et al., 2011) and burnout (Chang, 2012).

On the organizational level, researchers were especially interested in investigating how perfectionism can contribute to the development of burnout syndrome (Chang et al., 2014; Zhang, et al., 2007). Job burnout is a psychological syndrome that develops and progresses due to long-term work related stress. As defined by Maslach et al., burnout is "a syndrome of emotional exhaustion, depersonalization, and reduced accomplishment..." (Maslach, et al., 2001, p.189).

Like perfectionism, burnout is a multidimensional phenomenon that has three dimensions: emotional exhaustion, cynicism and inefficacy. Emotional exhaustion is the most manifested aspect of burnout where employees feel strained and tired. Cynicism is a coping technique to cope with situations that are perceived as stressful, where employees tend to create emotional distance between themselves and the people they serve and some time with the people they work with (Maslach, 2003). Finally, inefficacy is a feeling of reduced efficacy, where individuals negatively evaluate themselves, and suffer from feelings of incompetence and a lack of achievement and productivity at work (Leiter \& Maslach, 2009; Maslach, et al., 2001).

Perfectionism, as a personality trait, affects how individuals perceive and manage work stressors. Accordingly, it is expected to be significantly associated with burnout (Child \& Stoeber, 2012). For example, perfectionism was found to influence the individual's personal assessment of work demands and to explain the development of burnout (Hill et al., 2004).

Perfectionistic strivings are characterized by having a "perfectionistic motivation" where perfectionist beliefs that are striving for perfection and being perfect are important (Rasquinha, et al., 2014; Smith, et al., 2015). Accordingly, perfectionistic strivings are expected to be negatively correlated to burnout (Chang, 2012; Karimi, et al., 2014). In contrast, perfectionistic concerns comprise of externally motivated beliefs, where perfectionists believe that others expect excessively high standards from them and that fulfilling these standards is a must to gain others' acceptance (Child \& Stoeber, 2012; Hill, et al., 2010). These beliefs are associated with ongoing chronic stress which, in turn, evolves in burnout (Craiovan, 2014; Zhang, et al., 2007). Accordingly, it is expected that perfectionistic concerns are positively correlated with burnout (Rasquinha, et al., 2014; Smith, et al., 2015).

In Egypt, physicians are expected to have high levels of perfectionism. This is culturally true because medical professions are classified as a high standard profession and only students with distinguished academic performance can join medical schools. Egyptian physicians are exposed to chronic work stressors (e.g., excessive daily interactions with patients, handling enormous number of patients daily) which in turn may lead to burnout. So it is expected that they may suffer from burnout which may be 
amplified by their perfectionistic personality traits. Therefore, among Egyptian physicians, the following hypotheses can be proposed:

Hypothesis 1: Perfectionistic strivings are negatively correlated with burnout. Hypothesis 2: Perfectionistic concerns are positively correlated with burnout.

\subsection{THE MODERATING ROLE OF RELIGIOUS COPING}

Individuals who experience stress are more likely to suffer from negative psychological effects including depression, mental disorders and burnout (Maslach, et al., 2001). To alleviate these negative effects individuals use different coping strategies (Lazarous \& Folkman, 1984). As described by Belal and his colleagues (2009), coping strategies are ways used to minimize the effects of stress that individuals, groups or organizations experience.

Recently, an increasing interest toward studying the role of religion in coping with major life stressors was developed (Pargament et al., 2011). In their efforts to adapt with stressful times, individuals tend to turn to religion where they can find comfort and spiritual support (Ano \& Vasconcelles, 2005). Pargament emphasized the importance of religions in achieving happiness and wellbeing of individuals (Pargament, 1997). A significant body of research found that religious involvement is associated with wellbeing, mental and psychological health (Ismail \& Desmukh, 2012). It was found that individuals with strong religious faith report higher levels of life satisfaction, greater personal happiness and fewer negative psychological consequences for traumatic life events (Ellison, 1991).

Religious coping strategies are emotion-focused coping strategies (Bjorck, \& Thurman, 2007; Pargament et al., 1998). According to Pargament (1997) religious coping is described as efforts to understand and deal with life stressors in ways related to the "sacred". The term "sacred" refers not only to God (the ultimate power), but also to aspects of life that are associated with his qualities" (Pargament \& Mahoney, 2005). According to Pargament's theory, religious coping serves multiple functions including: search for meaning, intimacy with others, identity, control, anxiety-reduction, transformation, as well as the search for the sacred (God) or spirituality itself (Pargament, 1997; Pargament \& Mahoney, 2005).

Religious coping was found to be negatively correlated with stress (Kahnamouei et al., 2011; Maltby \& Day, 2003; Sipon et al., 2013) and burnout (Hastings \& Brown, 2002). Another line of research indicated that there are conceptual links between religious coping, different personality traits and burnout (Ferguson, 2001). For example, religious coping was able to moderate the relationship between the five big personality traits and alcohol abuse (Huhra, 2007).

As for perfectionism, it was found that some coping strategies - namely avoidance - moderate the relationship between perfectionism and psychological well-being (Fry, 1995). Religious coping was considered as kind of emotion-focused coping where instead of facing a problem or trying to solve it, people turn to religions asking for the help of the ultimate power (God) (Pargament, 1997). Researchers also found a significant relationship between religiosity and perfectionistic strivings, but not to perfectionistic concerns, suggesting that religious persons may be perfectionistic in adaptive rather than maladaptive ways (Ashby, \& Huffman, 1999; O'Connor, \& O'Connor, 2003). Based on the above discussions, the third hypothesis can be stated as follows:

Hypothesis 3: Religious Coping moderates the relationship between perfectionism and burnout

The conceptual model that describes the previous hypotheses is demonstrated in figure 1.

Figure 01: The hypothesised relationship 


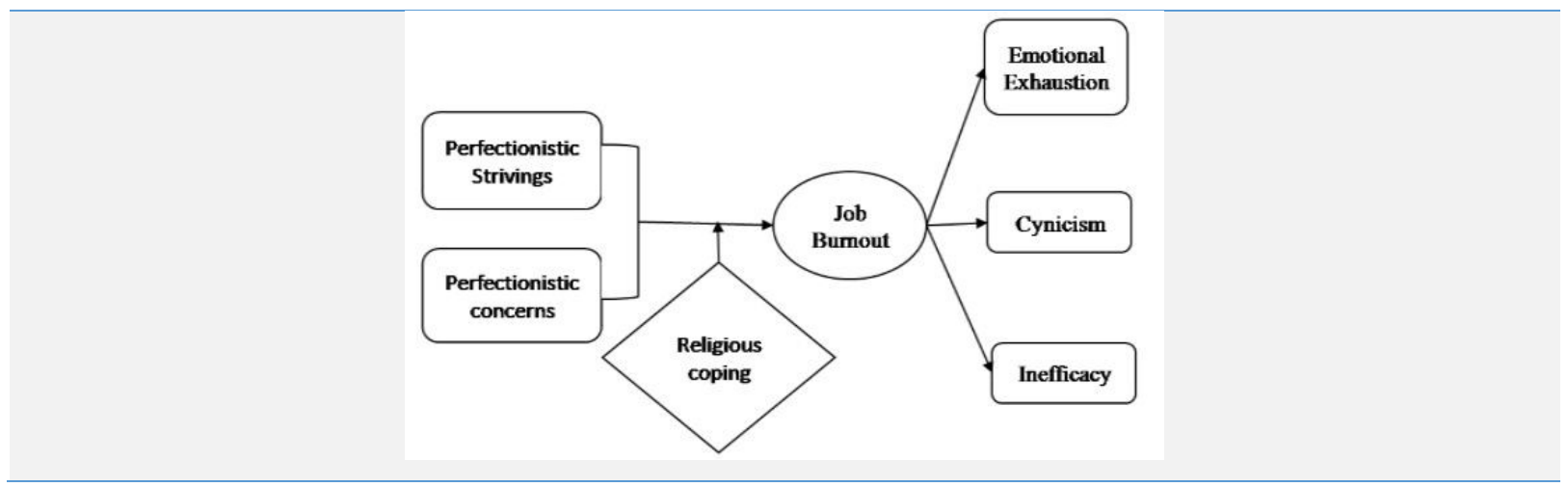

\subsection{DATA AND METHODOLOGIES}

\subsection{SAMPLE}

The target population in the current study is Egyptian physicians work in public $(\mathrm{N}=1848)$ and private ( $\mathrm{N}$ = 1836) medical institutes located in Greater Cairo area (Central Agency for Public Mobilization and Statistics, 2014). Using statistical power test at $\alpha=0.05, \beta=0.05$ and power $=0.95$, a sample size of 168 occurs to be suitable to achieve the research objectives. Using a simple random sampling technique, a sample of 270 physicians was targeted, only 218 of them responded (response rate $=80.7 \%$ ). In addition 8 responses were omitted for incomplete data, leaving 210 responses valid for analysis. Participants were visited in their workplaces and were asked to complete the questionnaire. Before distributing the questionnaire, all participants were assured that their participation was voluntary and anonymity was guaranteed. The age of participants ranged between 28 to 50 years with average 34.52 years and standard deviation of 6.87 years. Compared with female physicians, males were the majority in the sample $(58.8 \%)$. Most of physicians $(61 \%)$ has received a master degree, $28 \%$ has received a bachelor degree and only $11 \%$ has finished their doctorate degree. These characteristics indicate a reasonable mix of demographic groups represented in the data.

\subsection{MEASUREMENTS}

The short version of the Multidimensional Perfectionism Scale (MPS) (Cox et al., 2002) was used to measure the two forms of perfectionism: perfectionistic strivings ( 5 items) and perfectionistic concerns ( 5 items). Answers ranged from 1 (totally disagree) to 5 (totally agree).

Maslach Burnout Inventory ( $\mathrm{MBI}$ ) general survey was used to measure burnout. The scale has 16 items measuring three subscales: emotional exhaustion ( 5 items), cynicism ( 5 items), and inefficacy ( 6 items). Answers ranged from 1 (never) to 6 (every day) (Maslach et al., 1986).

To measure religious coping a modified version of the brief religious coping scale RCOPE scale was used (Pargament et al., 2011). The original scale contains 14 statements. The modified scale has 10 statements. The four negative religious statements were removed, based on the opinion of 5-expert panel, for inconvenience with the Egyptian culture (e.g., I questioned the power of God, I wondered whether my church had abandoned me). Answers ranged from 1 (totally disagree) to 5 (totally agree).

The three measures were translated into Arabic and a back translation procedure was used to guarantee the quality of translation and that the content of questions was not altered. Reversed items were indicated for the date entry. Moreover, to test the reliability of these questionnaires, Cronbach's alpha coefficients were calculated as shown in table 1. 


\begin{tabular}{|l|c|c|c|c|c|c|c|}
\hline \multicolumn{7}{|c|}{ Table 01: Cronbach's alpha of the used instruments } \\
\hline Scale & $\begin{array}{c}\text { Perfectionistic } \\
\text { Strivings }\end{array}$ & $\begin{array}{c}\text { Perfectionistic } \\
\text { Concerns }\end{array}$ & $\begin{array}{c}\text { Religious } \\
\text { Coping }\end{array}$ & $\begin{array}{c}\text { Emotional } \\
\text { Exhaustion }\end{array}$ & Cynicism & Inefficacy & $\begin{array}{c}\text { Total } \\
\text { Burnout }\end{array}$ \\
\hline $\begin{array}{l}\text { Alpha } \\
\text { Cronbach }\end{array}$ & .819 & .773 & .884 & .704 & .721 & .741 & .786 \\
\hline
\end{tabular}

\begin{tabular}{|c|c|c|c|c|c|c|c|c|c|c|c|c|}
\hline \multicolumn{13}{|c|}{ Table 02: Confirmatory factor analysis for used questionnaires items } \\
\hline \multirow[t]{2}{*}{ Items } & \multicolumn{2}{|c|}{ Emotional Exhaustion } & \multicolumn{2}{|c|}{ Cynicism } & \multicolumn{2}{|c|}{ Inefficacy } & \multicolumn{2}{|c|}{$\begin{array}{l}\text { Perfectionistic } \\
\text { Strivings }\end{array}$} & \multicolumn{2}{|c|}{$\begin{array}{l}\text { Perfectionistic } \\
\text { concerns }\end{array}$} & \multicolumn{2}{|c|}{ Religious Coping } \\
\hline & Estimate & t-value & Estimate & t-value & Estimate & t-value & Estimate & t-value & Estimate & t-value & Estimate & $t$-value \\
\hline 1 & 0.74 & $8.21 * *$ & 0.62 & $5.80 * *$ & .891 & $10.73^{* *}$ & .730 & $9.89 * *$ & .689 & $10.10 * *$ & .688 & $10.12^{* *}$ \\
\hline 2 & 0.83 & $9.01 * *$ & 1.03 & $10.68 * *$ & 1.033 & 12.14 ** & 1.309 & $9.78 * *$ & 1.189 & $9.38 * *$ & .736 & $11.19 * *$ \\
\hline 3 & 0.72 & $6.97 * *$ & 3.16 & $1.46^{*}$ & .559 & $5.59 * *$ & .842 & $8.24^{* *}$ & 1.057 & $8.62 * *$ & .946 & $13.12 * *$ \\
\hline 4 & 0.88 & $8.47^{* *}$ & 0.23 & $2.24^{* *}$ & .702 & $6.91 * *$ & .794 & $10.05^{* *}$ & .952 & $8.54^{* *}$ & .780 & $10.94^{* *}$ \\
\hline 5 & 2.12 & $1.21 *$ & 0.88 & $9.33^{* *}$ & .990 & $12.01 * *$ & .723 & $8.87^{* *}$ & .971 & $8.61 * *$ & .917 & $14.11 * *$ \\
\hline 6 & & & & & .606 & $5.98 * *$ & & & & & .817 & $12.85^{* *}$ \\
\hline 7 & & & & & & & & & & & .410 & $6.95^{* *}$ \\
\hline 8 & & & & & & & & & & & .654 & $8.76 * *$ \\
\hline 9 & & & & & & & & & & & .517 & $10.94^{* *}$ \\
\hline 10 & & & & & & & & & & & .627 & $9.38 * *$ \\
\hline
\end{tabular}

The reliability measures, in terms of Cronbach's alpha, were above the recommended level of 0.70 as an indicator for adequate internal consistency (Hair et al., 2010). Further, to test the validity of the used questionnaires, two main procedures were used. First, the questionnaires were revised by a panel of 5 experts who assessed the content of each questionnaire and evaluated the appropriateness of these contents to the Egyptian culture. The comments of all experts, after removing 4 items form RCOPE, indicated that the used questionnaires are valid and culturally appropriate. Second, a confirmatory factor analysis, using AMOS 20, was conducted to confirm the factor structures of the used scales in the Egyptian culture as shown in table 2.

It can be shown from the above results that all questionnaires' items have significant factor loadings on their latent variables. The fit indices for the factor structures of the used measurements are shown in table 3. 


\begin{tabular}{|lcccccc|}
\hline \multicolumn{8}{c|}{ Table 03: Fit indices for the factor structures of the used measurements } \\
\hline Variable & CMIN/DF & GFI & AGFI & NFI & CFI & RMSEA \\
\hline Emotional Exhaustion & 1.965 & .987 & .951 & .953 & .976 & .066 \\
Cynicism & 1.771 & .994 & .953 & .984 & .993 & .059 \\
Inefficacy & 1.878 & .980 & .848 & .962 & .967 & .049 \\
Perfectionistic Strivings & 1.490 & .975 & .937 & .965 & .988 & .047 \\
Perfectionistic concerns & 1.387 & .966 & .958 & .961 & .965 & .038 \\
Religious Coping & 1.638 & .988 & .974 & .987 & .991 & .001 \\
\hline
\end{tabular}

All fit indices were above the recommended levels of acceptance. Therefore, it can be concluded that the factor structures of the used measurements are confirmed in the Egyptian culture.

\subsection{RESULTS AND DISCUSSION}

The statistical package for social sciences (SPSS 20) was used to analyse the collected data in order to test the proposed hypotheses. First, to examine the relationships among study variables, Pearson correlation coefficients were calculated as shown in table 4 along with the descriptive statistics.

The descriptive statistics in the table 4 indicate that Egyptian physicians are suffering from moderate levels of burnout. Moreover, it can be shown from the correlation matrix that perfectionistic strivings are negatively correlated with emotional exhaustion and feelings of inefficacy as well as with the total score of burnout. However, no significant correlation was found between perfectionistic strivings and cynicism. These results give partial support for the first hypothesis.

\begin{tabular}{|c|c|c|c|c|c|c|c|c|c|}
\hline \multicolumn{2}{|c|}{ Variable } & & $\mathrm{s}$ & 1 & & 2 & 1 & $\Gamma$ & \\
\hline 1 & Perfectionistic Strivings & 1504 & 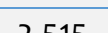 & 1 & & & & & \\
\hline 2 & Perfectionistic concerns & $10 \cdot 94$ & 2.313 & $67^{* *}$ & 1 & & & & \\
\hline 2 & Reliơins Conino & $\begin{aligned} 19.31 \\
2751\end{aligned}$ & 4.909 & .407 & 202 ** & & & & \\
\hline 3 & Fmotional Fxhaustion & $\begin{array}{l}32 \cdot 34 \\
1201\end{array}$ & $3.4 / 1$ & $-248^{* *}$ & $.203 *$ & $-157^{*}$ & 1 & & \\
\hline 5 & Cynicism & 11.48 & 3.688 & -.036 & .049 & .011 & $.458^{* *}$ & 1 & \\
\hline 6 & Inefficacy & 13.82 & 4.659 & $-.313^{* *}$ & .060 & $-.246^{* *}$ & $.558^{* *}$ & $.431^{* *}$ & 1 \\
\hline 7 & Total Burnout & 36.24 & 9.808 & $-.239^{* *}$ & $.168 *$ & $-.173^{* *}$ & $.819^{* *}$ & $.755^{* *}$ & $.850^{* *}$ \\
\hline
\end{tabular}

In addition, perfectionistic concerns were positively correlated with emotional exhaustion and the total score of burnout but not with cynicism and feelings of inefficacy which gives a partial support for the second hypothesis as well.

In order to test the moderating effect of religious coping in the relationship between perfectionism and burnout, hierarchical regression analyses were conducted to examine the interactions between the standardized scores of perfectionism and religious coping. The results are shown in table 5 .

The results of hierarchical regressions indicated that there are no significant interactions effects between perfectionism (Perfectionistic Strivings or Perfectionistic concerns) and religious coping on physicians' burnout. Therefore, it can be concluded that religious coping does not moderate the relationship between perfectionism and burnout. Thus the third hypothesis was not supported.

\begin{tabular}{|llcccc|}
\hline \multicolumn{5}{c}{ Table 05: Hierarchical regressions to test the moderating effects of religious coping } \\
\hline Dependent variable & Independent variable & B & t-value & R-square & F \\
\hline Burnout & Z- Perfectionistic Strivings & -2.612 & $-3.08^{* *}$ & 0.071 & $5.51^{* *}$ \\
& Z- Religious Coping & -2.137 & $-2.43^{* *}$ & & \\
Burnout & Interaction & -0.575 & -1.51 & & \\
& Z - Perfectionistic concerns & 2.251 & $2.84^{* *}$ & 0.053 & $3.45^{* *}$ \\
& Z- Religious Coping & -1.902 & $-2.41^{* *}$ & \\
& Interaction & -0.129 & -0.245 & \\
\hline
\end{tabular}


The previous results partially supported the first hypothesis were perfectionistic strivings were found to be negatively correlated with emotional exhaustion and feelings of inefficacy as well as with the total score of burnout. The second hypothesis was also partially supported as perfectionistic concerns were positively correlated with emotional exhaustion and with total score of burnout but not with cynicism and feelings of inefficacy.

These results give support to previous research (Chang, et al., 2015; Karimi, et al., 2014; Luo et al., 2016). Individuals with perfectionistic strivings set high, but, rational and realistic standards and generally tend to believe that they can achieve those standards (Smith, et al., 2015). Out of their belief that being perfect is important, perfectionistic striving individuals are committed, hardworking and high performing, hence, they are more likely to be satisfied in both work and life which, in return, reduce burnout. (Chang, 2012; Child \& Stoeber, 2012; Rasquinha, et al., 2014). On the other hand, Individuals with perfectionistic concerns are externally motivated. They seek the acceptance of others through their efforts to meet others' expectations and standards which, they believe, are excessively high standards (Hill, et al., 2010). These beliefs generate chronic stress that evolves in burnout (Craiovan, 2014; Karimi, et al., 2014).

The relationship between perfectionism and burnout has been supported by previous research. However, the relationships between perfectionism and burnout dimensions are questionable. Some researchers confirmed the relationship between perfectionism and the three dimensions of burnout (e.g., Child \& Stoeber, 2012; Karimi, et al., 2014; Rasquinha, et al., 2014; Smith, et al., 2015) whereas, others confirmed the relationship with only one or two dimensions of burnout (Kanten \& Yesiltas, 2015; Schaufeli, et al., 2008).

In addition, the results indicated significant correlation between the two dimensions of perfectionism and emotional exhaustion. Emotional exhaustion was found in most researches to be negatively correlated to perfectionistic strivings (Karimi, et al., 2014; Luo et al., 2016). Emotional exhaustion, the main and most revealing dimension of burnout, is characterized as feelings of emotionally overextended, extreme tired, depleted and feeling of energy loss (Leiter \& Maslach, 2009; Maslach, et al., 2001). Perfectionistic strivings are considered as an internal motive that increases the energy (Rasquinha, et al., 2014). Accordingly, it is expected that the more perfectionistic striving a person is, the more energized and less emotionally exhausted.

On the other hand, perfectionistic concerns, as an external motive, impose more stress on individuals to give their best efforts to achieve high performance standards, they belief, others are expecting from them (Karimi, et al., 2014; Luo et al., 2016; Smith, et al., 2015). In contrast with these findings, Kanten \& Yesiltas (2015) found that both Perfectionistic strivings (positive perfectionism) and perfectionistic concerns (negative perfectionism) affect psychological well-being positively, whereas they have no direct effect on emotional exhaustion. This was explained by the mediating effect of psychological wellbeing where psychological well-being can eliminate the effect of both perfectionistic strivings and concerns. In other words, perfectionism (strivings and concerns) affect employees' psychological wellbeing, and it is the psychological well-being that can affect emotional exhaustion levels through time (Kanten, \& Yesiltas, 2015). This can be explained by another study, where burnout, engagement and workholism, were found to be three different kinds of employee well-being rather than being three different constructs (Schaufeli et al. 2008). Accordingly, it could be enlightening to study the interaction between psychological well-being and burnout dimensions.

As for feelings of inefficacy, it was found to have a negative correlation with perfectionistic strivings. This result is supported by past research (e.g., Luo et al., 2016; Smith, et al., 2015; Zhang, et al., 2007). Moreover, feeling of inefficacy was not correlated significantly with perfectionistic concerns. However, the previous literature shows inconsistency in this respect (see for example, Karimi, et al., 2014; Rasquinha, et al., 2014; Smith, et al., 2015). Perfectionistic striving individuals tend to have a positive mood with high levels of psychological well-being, self-esteem and self-confidence derived from their success in achieving their desired performance standards (Lo \& Abbott, 2013; Stoeber \& Otto, 2006). Perfectionistic strivings are willing to learn new things, and tend to accept additional responsibilities 
(Kanten \& Yesıltas, 2015). This could increase their feeling of accomplishment and self-esteem, hence, decrease feelings of inefficacy.

On the other hand, perfectionistic concerns (named as unhealthy perfectionism) were found to be associated with lack of self-esteem where an area of interaction exists between perfectionism and selfesteem (Stumpf \& Parker, 2000). In other words, people with perfectionistic concerns could be characterised as law self-steam individuals, with main concerns about others' approval. The reason why perfectionistic concerns were not correlated with feelings of inefficacy in burnout scale, according to Stumpf \& Parker (2000), is the interaction between perfectionistic concerns and self-esteem. Hence, feelings of inefficacy are not caused by the effects of the negative feelings created by concerns over others' reactions to imperfection, but due to the low self-esteem. Thus, it could be important to study the interactions between self-esteem and feelings of inefficacy in burnout.

For the third dimension of burnout, namely cynicism, the results did not show any significant correlation with perfectionistic strivings or perfectionistic concerns. Once again, this is an area of inconsistent results (see for example, Chang et al, 2015; Smith, et al., 2015; Zhang, et al., 2007). In their study on working women, Mitchelson and Burns (1998) found no correlation between perfectionistic strivings (positive perfectionism) and cynicism whereas, they found a positive correlation between perfectionistic concerns (negative perfectionism) and cynicism at work and parental distress at home. Working women with negative perfectionism worries about others' opinions as they think that others are questioning their value. Hence, they work hard and desperately try to prove their worthiness. As work seems to be the domain for that value, they focus on getting the job done even if they scarifice their personal life (parental distress at home).

In their journey to convince others of their value in work, they seem to be over involved in work and they create a distance from people and experience cynicism at work (Mitchelson and Burns 1998). The same result was found by Child, \& Stoeber, (2010) where perfectionistic strivings (self-oriented perfectionism) showed no correlation with all dimensions of burnout, while perfectionistic concerns (Other-oriented perfectionism) showed a significant but negative correlation with cynicism.

The results support the existence of significant positive correlation between Religious coping and perfectionistic strivings. Correlation with perfectionistic strivings was relatively strong $\left(r=.501^{* *}\right)$ which could be explained by religious beliefs as striving for perfectionism is considered as a main Religious belief (Pargament \& Mahoney, 2005). Perfectionistic concerns were negatively correlated to religious coping which lend support to Crosby, et al (2011) and contrast with other previous researchers (e.g., O'Connor, \& O'Connor, 2003). This could be explained by the buffering model introduced by Smith, et al., (2015).

According to that model, perfectionistic strivings buffer against the negative effects of perfectionistic concerns. This could be explained also by the nature of religions itself, as religions are somehow a personal relationship between the person and God. Hence, individuals who use Religious coping are more likely to focus on developing their inner relief and comfort and life satisfaction instead of thinking about others (Pargament et al. 2005). In the studied cultural context, both Islamic and Christian advocates believe that they should start by themselves and not care about others' opinions. Yet, more studies are required to investigate the relationship between both perfectionistic strivings and perfectionistic concerns and religious coping.

The results also support the existence of significant negative correlation between religious coping and burnout. This lend support to other researches (Hastings \& Brown, 2002; Maltby \& Day, 2003). Religious coping was found to be negatively correlated with stress and burnout as it alleviates the effects of stressful, unhappy events. People who use religious coping tend to belief that God has a good wise reason behind stressful events, hence they tend to cope with these events with more peaceful mind even in very stressful events and situations (Pargament \& Mahoney, 2005).

Nevertheless, the results of this study did not support the third hypothesis assuming that religious coping moderates the relationship between perfectionism and physicians' burnout. This result can be explained 
in the light of the severity of stress created by perfectionism. David \& Suls (1999) found that people tend to turn to religious coping strategies mainly in severe stress conditions. Although perfectionism imposes stress on Egyptian physicians, these stressors may not be appraised as severe stressors that require turning to religious coping strategies. This explanation is supported by the moderate level of burnout that physicians experienced as indicated by the descriptive statistics. However, the moderating role of religious coping with different level of stress severity deserves to be studied in depth.

Our research has valuable contributions; however, our results should be interpreted with caution since they may be driven by the nature of business and the cultural context they occur within.

\subsection{CONCLUSIONS AND POLICY IMPLICATIONS}

This study aimed at investigating perfectionism among Egyptian physicians and its relation to burnout. The moderating effect of religious coping on this relationship was also investigated. The results supported the existence of a correlation between perfectionism and burnout among Egyptian physicians. Perfectionistic concerns were the dominant dimension of perfectionism among Egyptian physicians with a moderate level of burnout. Perfectionistic strivings were found to be negatively correlated with emotional exhaustion and feelings of inefficacy as well as with the total score of burnout. Perfectionistic concerns were positively correlated with emotional exhaustion and with total score of burnout but not with cynicism and feelings of inefficacy. Egyptian physicians scored relatively high on religious coping with a significant positive correlation between religious coping and both perfectionistic strivings and perfectionistic concerns, whereas a negative significant correlation was found with emotional exhaustion, feelings of inefficacy and total score of burnout. However, the moderating role of religious coping was not confirmed in the studied context.

These results have several practical implications. First, the fact that perfectionistic concerns were the dominant dimension among Egyptian physicians expresses the social pressure perceived by physicians to be perfect. This imposes daily stress on them and requires relevant coping strategy to alleviate this stress. Second, the moderate level of burnout with a sample with average age 34.52 years could be an alarm for policy makers to investigate the possible reasons of burnout among Egyptian physicians. In addition, several employees' assistance programs (EAP's) can be provided by the Egyptian ministry of health to help Egyptian physicians cope better with job stress and to avoid job burnout.

In addition to the previous practical implications, several theoretical insights can be introduced as directions for future research. These include, but are not limited to, the following:

- First, the interaction between burnout, psychological well-being and engagement was clear in researches and it seems to have some overlap that they seem to be one construct with multiple facets. Hence more research is needed to clarify the exact nature of these overlapping constructs.

- Second, the relationship between perfectionism and cynicism needs to be clarified as results were contradicting in this area. Perfectionistic strivings could drive individuals to be more individualistic which a negative side for a positive dimension. On the hand, Perfectionistic concerns could lead individuals to more socialization and less cynicism in their striving for acceptance and recognition for their performance.

- Third, more research is needed to investigate the relationship between both perfectionistic strivings and perfectionistic concerns and religious coping. The significant correlation with religious coping raises a question about stress severity caused by perfectionism.

- Finally, the moderating role of religious coping needs to be investigated in relation to daily stressors and severe stressors within different cultural and occupational contexts.

\section{REFERENCES}

Ano, G. \& Vasconcelles, E. (2005). Religious coping and psychological adjustment to stress: A metaanalysis. Journal of Clinical Psychology, 61(4), 1-20. 
Ashby, J. \& Huffman, J. (1999). Religious orientation and multidimensional perfectionism: Relationships and implications. Counseling and Values, 43(3), 178-188.

Belal B., Hassan Y., \& Rusnah M. (2009). Religiosity and work stress coping behavior of Muslim employees, Education, Business and Society: Contemporary Middle Eastern Issues, 2(2), 123-137

Bergman, A., Nyland, J., \& Burns, L. (2007). Correlates with perfectionism and the utility of a dual process model. Personality and Individual Differences, 43(2), 389-399.

Bieling, P., Israeli, A., \& Antony, M. (2004). Is perfectionism good, bad, or both? Examining models of the perfectionism construct. Personality \& Individual Differences, 36(6), 1373.

Bjorck J., \& Thurman J. (2007). Negative life events, patterns of positive and negative religious coping, and psychological functioning. Journal for the Scientific Study of Religion, 46(2), 159-167.

Cano-Garcia, F., Padilla-Muñoz, E., \& Carrasco-Ortiz, M. (2005). Personality and contextual variables in teacher burnout. Personality and Individual Differences, 38(4), 929-940.

Central Agency for Public Mobilization and Statistics (2014). The annual bulletin of statistics of health services. Cairo: CAPMAS.

Chang, E., Lee, A., Byeon, E., Seong, H., \& Lee, S. (2015). Role of motivation in the relation between perfectionism and academic burnout in Korean students. Personality and Individual Differences, 82(15), 221-226.

Chang, Y. (2012). The relationship between maladaptive perfectionism with burnout: Testing mediating effect of emotion-focused coping. Personality and Individual Differences, 53(5), 635-639.

Child, J., \& Stoeber, J. (2010). Self-oriented, other-oriented, and socially prescribed perfectionism in employees: Relationships with burnout and engagement. Journal of Workplace Behavioral Health, 25(4), 269-281.

Child, J. \& Stoeber, J. (2012). Do you want me to be perfect? Two longitudinal studies on socially prescribed perfectionism, stress and burnout in the workplace. Work \& Stress, 26(4), 347-364.

Cox, B., Enns, M., \& Clara, I. (2002). The multidimensional structure of perfectionism in clinically distressed and college student samples. Psychological Assessment, 14, 365-373.

Craiovan, P. (2014). Correlations between perfectionism, stress, psychopathological symptoms and burnout in the medical field. Procedia - Social and Behavioral Sciences, 127(22), 529-533.

Crosby, J., Bates, S., \& Twohig, M. (2011). Examination of the relationship between perfectionism and religiosity as mediated by psychological inflexibility. Current Psychology, 30(2), 117-129

David, J., \& Suls, J. (1999). Coping efforts in daily life: Role of big five traits and problem appraisals. Journal of Personality, 67(2), 265-294

Dakanalis, A., Timko, A., Zanetti, A., Rinaldi, L., Prunas, A., Carrà, G., Riva, G., \& Clerici, M. (2014). Attachment insecurities, maladaptive perfectionism, and eating disorder symptoms: A latent mediated and moderated structural equation modeling analysis across diagnostic groups. Psychiatry Research, 215(1), 176-184.

Ellison C. (1991). Religious involvement and subjective well-being. Journal of Health and Social Behavior, 32(1), 80-99.

Eum, K., Rice, K. (2011). Test anxiety, perfectionism, goal orientation, and academic performance. Anxiety, Stress, \& Coping, 24(2), 167-178.

Fedewa, B., Burns, L., \& Gomez, A. (2005). Positive and negative perfectionism and the shame/guilt distinction: Adaptive and maladaptive characteristics. Personality and Individual Difference, 38(7), 1609-1619.

Ferguson, E. (2001). Personality and coping traits: A joint factor analysis. British Journal of Health Psychology, 6(4), 311-325.

Flett, G., \& Hewitt, P. (2002). Perfectionism and maladjustment: An overview of theoretical, definitional, and treatment issues. In: P. L. Hewitt \& G. L. Flett (Eds.). Perfectionism (pp. 5-31). Washington, DC: American Psychological Association.

Fry, P. (1995). Perfectionism, humor, and optimism as moderators of health outcomes and determinants of coping styles of women executives. Genetic, Social, and General Psychology Monographs, 121(2), $211-245$.

Gandi, J., Wai, P., Karick, H., \& Dagona, Z. (2011). The role of stress and level of burnout in job performance among nurses. Mental Health in Family Medicine, 8(3), 181-194. 
Hair, J., Black, W., Babin, B., \& Anderson, R. (2010). Multivariate Data Analysis. Seventh Edition. New Jersey: Prentice Hall, Upper Saddle River,

Hallsten, L., Voss, M., Stark, S., Josephson, M., \& Vingård, E. (2011) Job burnout and job worn-out as risk factors for long term sickness absence. Work, 38(2), 181-192.

Hastings, R. \& Brown, T. (2002). Coping strategies and the impact of challenging behaviors on special educators' burnout. Mental Retardation, 40(2), 148-156.

Hill, R., Huelsman, T., Furr, R., Kibler, J., Vicente, B., \& Kennedy, C. (2004). A new measure of perfectionism: The perfectionism inventory. Journal of Personality Assessment, 82(1), 80-91.

Huggins, L., Davis, M., Rooney, R., \& Kane, R. (2008). Socially prescribed and self-oriented perfectionism as predictors of depressive diagnosis in pre adolescents. Australian Journal of Guidance and Counseling, 18(2), 182-194.

Huhra, R. (2007). Religious coping as a moderator of the five-factor model of personality traits and alcohol abuse severity at six-month follow-up in a twelve-step treatment sample. (Electronic Thesis and Dissertation). Retrieved from https://etd.ohiolink.edu

Ismail, Z., \& Desmukh, S., (2012). Religiosity and psychological well-Being. International Journal of Business and Social Science, 3(11), 20-28.

Jahromi, F., Naziri, G., \& Barzegar, M. (2012). The relationship between socially prescribed perfectionism and depression: The mediating role of maladaptive cognitive schemas. Procedia - Social and Behavioral Sciences, 32(12), $141-147$.

Kahnamouei, S., Bazmi, M., \& Allahvirdiyan, K. (2011). Relationship of religious orientation (inwardoutward) with depression, anxiety and stress. Procedia - Social and Behavioral Sciences, 30(11), 20472049.

Kanten, P. \& Yesiltas, M. (2015). The effects of positive and negative perfectionism on work engagement, psychological well-being and emotional exhaustion. Procedia Economics and Finance, 23(15), 13671375.

Karimi, Y., Bashirpur, M., Khabbaz, M., Hedayati, A. (2014). Comparison between perfectionism and social support dimensions and academic burnout in students. Procedia - Social and Behavioral Sciences, 159(23), 57-63.

Kempke, S., Houdenhove, B., Luyten, P., Goossens, L., Bekaert, P., \& Wambeke, P. (2011). Unraveling the role of perfectionism in chronic fatigue syndrome: Is there a distinction between adaptive and maladaptive perfectionism? Psychiatry Research, 186 (2-3), 373-377.

Kim, H., Shin, K., \& Swanger, N. (2009). Burnout and engagement: A comparative analysis using the big five personality dimensions. International Journal of Hospitality Management, 28(1), 96-104.

Klibert, J. \& Langhinrichsen-Rohling, J. \& Saito, M. (2005). Adaptive and maladaptive aspects of selforiented versus socially prescribed perfectionism. Journal of College Student Development, 46(2), 10-13.

Kobori, O., \& Tanno, Y. (2005). Self-oriented perfectionism and its relationship to positive and negative affect: The mediation of positive and negative perfectionism cognitions. Cognitive Therapy \& Research, 29(5), 555-567.

Landa, C., \& Bybee, J. (2007). Adaptive elements of aging: Self-image discrepancy, perfectionism, and eating problems. Developmental Psychology, 43(1), 83-93.

Lazarus, R. \& Folkman, S. (1984). Stress, appraisal, and coping. New York: Springer.

Leiter, M., \& Maslach C. (2009). Nurse turnover: The mediating role of burnout. Journal of Nursing Management, 17(3), 331-339.

Li, X., Hou, Z., Chi, H., Liu, J. \& Hager, M., (2014). The mediating role of coping in the relationship between subtypes of perfectionism and job burnout: A test of the $2 \times 2$ model of perfectionism with employees in China. Personality and Individual Differences, 58(1), 65-70.

Lo, A., \& Abbott, M. (2013). Review of the theoretical, empirical, and clinical status of adaptive and maladaptive perfectionism. Behavior Change, 30(2), 96-116.

Longbottom, J., Grove, R., \& Dimmock, J. (2012). Trait perfectionism, self-determination, and selfpresentation processes in relation to exercise behavior. Psychology of Sport and Exercise, 13(2), 224235 . 
Luo, Y., Wang, Z., Zhang, H., Chen, A., \& Quan, S. (2016). The effect of perfectionism on school burnout among adolescence: The mediator of self-esteem and coping style. Personality and Individual Differences, 88(1), 202-208.

Maltby, J., \& Day, L. (2003). Religious orientation, religious coping and appraisals of stress: assessing primary appraisal factors in the relationship between religiosity and psychological well-being. Personality and Individual Differences, 34(7), 1209-1224.

Maslach, C. (2001). What have we learned about burnout and health? Psychology \& Health, 16(5), 607612.

Maslach, C. (2003). Job burnout: New directions in research and intervention. Current Directions in Psychological Science, 12(5), 189-193.

Maslach, C., Jackson, S., Leiter, M., Schaufeli, W., \& Schwab, R. (1986). Maslach burnout inventory, $3^{\text {rd }}$ edition. Mind Garden, Inc.

Maslach, C., Schaufeli, W., \& Leiter, M. (2001). Job burnout. Annual Review of Psychology, 52(1), 397-422.

Mitchelson, J., \& Burns L. (1998). Career mothers and perfectionism: stress at work and at home. Personality and Individual Differences. 25(3), 477-485.

Nayeri, N., Negarandeh, R., Vaismoradi, M., Ahmadi, F. \& Faghihzadeh, S. (2009). Burnout and productivity among Iranian nurses. Nursing \& Health Sciences. 11(3), 263-270.

O'Connor, R. \& O'Connor, D. (2003). Predicting hopelessness and psychological distress: The role of perfectionism and coping. Journal of Counseling Psychology, 50(3), 362-372.

Ozyurt, A., Hayran, O., \& Sur, H. (2006). Predictors of burnout and job satisfaction among Turkish physicians. QJM: An International Journal of Medicine, 99(3), 161-169.

Pargament, K. (1997). The psychology of religion and coping: Theory, research, practice. New York: Guilford Press.

Pargament, K., Feuille, M., \& Burdzy, D. (2011). The Brief RCOPE: Current psychometric status of a short measure of religious coping. Religions, 2(1), 51-76.

Pargament, K., \& Mahoney, A. (2005). Sacred matters: Sanctification as a vital topic for the psychology of religion. Journal of Scientific Study of Religion. 15(3), 179-198.

Pargament K., Smith, B., Koenig, H., \& Perez, L. (1998). Patterns of positive and negative religious coping with major life stressors. Journal for the Scientific Study of Religion, 37(4), 710-724.

Rasquinha, A., Dunn, J., \& Dunn, J. (2014). Relationships between perfectionistic strivings, perfectionistic concerns, and competitive sport level. Psychology of Sport and Exercise, 15(6), 659-667.

Schiena, R., Luminet. O., Philippot, P., \& Douilliez, C. (2012). Adaptive and maladaptive perfectionism in depression: Preliminary evidence on the role of adaptive and maladaptive rumination. Personality and Individual Differences, 53(6), 774-778.

Schaufeli, W., Taris, T., Rhenen, W. (2008). Workaholism, Burnout, and Work Engagement: Three of a Kind or Three Different Kinds of Employee Well-being? Applied Psychology: An International Review, 57(2), 173-203.

Shanafelt, T., Boone, S., Tan, L., Lotte, N., Sotile, W., Satele, D., West, C., Sloan, J., \& Oreskovich, M. (2012). Burnout and satisfaction with work-life balance among US physicians relative to the general US population. JAMA Internal Medicine, 172(18), 1377-1385.

Sipon S., Nasrah, S., Nazli, N., Abdullah, S., \& Othman, K. (2014). Stress and religious coping among flood victims. Procedia - Social and Behavioral Sciences, 140(1), 605-608.

Skodova, Z. \& Lajciakova, P. (2013). The effect of personality traits and psychosocial training on burnout syndrome among healthcare students. Nurse Education Today, 33(11), 1311-1315.

Smith, M., Saklofske, D., Yan, G., Sherry, S. (2015). Perfectionistic strivings and perfectionistic concerns interact to predict negative emotionality: Support for the tripartite model of perfectionism in Canadian and Chinese university students. Personality and Individual Differences, 81(1), 141-147.

Spickard A., Gabbe, S., \& Christensen, J. (2002). Mid-career burnout in generalist and specialist physicians. JAMA, 288(12), 1447-1450.

Stoeber, J., \& Otto, K. (2006). Positive conceptions of perfectionism: Approaches, evidence, challenges. Personality and Social Psychology Review, 10(4), 295-319.

Stoeber. J., \& Stoeber, F. (2009). Domains of perfectionism: Prevalence and relationships with perfectionism, gender, age, and satisfaction with life. Personality and Individual Differences, 46(4), 530-535. 
Stumpf, H., \& Parker, W. (2000). A hierarchical structural analysis of perfectionism and its relation to other personality characteristics. Personality and Individual Differences, 28(5) 837-852.

Swider, B., \& Zimmerman, R. (2010). Born to burnout: A meta-analytic path model of personality, job burnout, and work outcomes. Journal of Vocational Behavior, 76(3), 487-506.

Toppinen, T., Salla, O., Anneli, V., Ari, K. \& Raija, J. (2005). Burnout as a predictor of medically certified sick-leave absences and their diagnosed causes. Behavioral Medicine. 31(1), 18-27.

Zhang Y., Gan, Y., \& Cham, H. (2007). Perfectionism, academic burnout and engagement among Chinese college students: A structural equation modeling analysis. Personality and Individual Differences, 43(6), 1529-1540. 